\title{
Diffusion coefficients of metal acetylacetonates in supercritical
}

\section{carbon dioxide}

Chang Yi Kong ${ }^{\text {a,* }}$, Yuan Yuan Gu ${ }^{\mathrm{a}}$, Masato Nakamura ${ }^{\mathrm{a}}$, Toshitaka Funazukuri ${ }^{\mathrm{b}}$, Seiichiro Kagei $^{\mathrm{c}}$

a Department of Materials Science and Chemical Engineering, Faculty of Engineering, Shizuoka University, 3-5-1 Johoku Naka-ku, Hamamatsu 432-8561, Japan

${ }^{\mathrm{b}}$ Department of Applied Chemistry, Faculty of Science and Engineering, Chuo University, Kasuga 1-13-27, Bunkyo-ku, Tokyo, 112-8551, Japan.

${ }^{c}$ Faculty of Environment and Information Sciences, Yokohama National University, 79-7 Tokiwadai, Hodogaya-ku, Yokohama 240-8501, Japan

* Corresponding author.

Tel.: +81-53-478-1174; fax: +81-53-478-1174.

E-mail address: tcykong@ipc.shizuoka.ac.jp (C. Y. Kong). 


\begin{abstract}
Abstrat
Binary diffusion coefficients, $D_{12}$, of metal acetylacetonates such as palladium(II) acetylacetonate and cobalt (III) acetylacetonate were measured from 308.2 to $343.2 \mathrm{~K}$ over the pressure range from 9.0 to $40.0 \mathrm{MPa}$ at infinite dilution in supercritical carbon dioxide using the chromatographic impulse response method. The effects of pressure, temperature, density, and viscosity on $D_{12}$ values were examined. It was observed that the $D_{12}$ values of palladium(II) acetylacetonate and cobalt (III) acetylacetonate were larger than those of lipids with similar molecular weights, such as arachidonic acid and monoolein, respectively. Furthermore, the measured $D_{12}$ data of each metal acetylacetonate were well correlated by the hydrodynamic equation $D_{12} / T$ as a function of carbon dioxide viscosity.
\end{abstract}

Keywords: Diffusion coefficient, Supercritical carbon dioxide, Metal acetylacetonate, CIR method 


\section{Introduction}

Supercritical fluid technology is a rapidly growing field due to the desirable properties as a promising alternative to the use of harmful organic solvents. As the high-pressure technology has nowadays progressed, the use of supercritical fluid is of great interest for designing green processes [1].

Organometalic complexes such as metal acetylacetonates are being extensively employed in preparation and processing of advanced functional materials as catalysts or precursors. Recently, the industrial application of combination of metal complexes and supercritical carbon dioxide is one of new research areas with significant potential [2,3]. In the accurate design and optimization of industrial processes with use of metal complexes, the estimation of mass transfer properties for the compounds becomes of particular importance. Especially, diffusion coefficients not only are necessary in engineering calculation for industrial design, but also provide basic information on the molecular interactions and structure of metal complexes in supercritical carbon dioxide. However, the binary diffusion coefficients of metal complexes, in particular, metal acetylacetonates are very scarce. As far as the authors know, only one report [4] on binary diffusion coefficients of copper(II) trifluoroacetylacetonate in supercritical carbon dioxide is available. Clearly, the diffusion data of various metal complexes in supercritical carbon dioxide are needed. Thus, the objectives of this study are to measure binary diffusion coefficients of metal acethylacetonates such as palladium(II) acethylacetonate $\left(\mathrm{Pd}(\mathrm{acac})_{2}\right.$, molecular weight $\left.=304.6\right)$ and cobalt (III) acethylacetonate $\left(\mathrm{Co}(\mathrm{acac})_{3}\right.$, molecular weight $\left.=356.3\right)$ in supercritical carbon dioxide by the chromatographic impulse response (CIR) method, and to correlate them with an appropriate equation. 


\section{Theory}

The theory of the CIR technique has been described in detail previously [5,6], in here, briefly described. When a tracer is pulse injected into a fully developed laminar flow in a coated cylindrical diffusion column, the cross-sectional average concentration $C(t)$ can be described as follows:

$$
\begin{aligned}
& C(t)=\left(\frac{m}{\pi R^{2}}\right) \frac{1}{(1+k)(4 \pi a t)^{1 / 2}} \exp \left\{-\frac{\left(L-u_{0} t /(1+k)\right)^{2}}{4 a t}\right\} \\
& a=\frac{D_{12}}{1+k}+\frac{1+6 k+11 k^{2}}{(1+k)^{3}} \frac{R^{2} u_{0}^{2}}{48 D_{12}}
\end{aligned}
$$

where $t$ is the time, $m$ the amount of solute, $R$ the radius of diffusion column, $k$ the retention factor, $L$ the distance, $u_{0}$ the average velocity of fluid, and $D_{12}$ the infinite dilution binary diffusion coefficient of the solute. When $u_{0}$ is measured experimentally, $D_{12}$ and $k$ can be simultaneously determined by minimizing the root-mean-square (rms) fitting error $\varepsilon$, defined by Eq. (3), for the measured $C_{\exp }(t)$ and calculated $C(t)$ curves. The curve fit is considered good when $\varepsilon<1 \%$, and acceptable when $\varepsilon<2 \sim 3 \%$ [6].

$\varepsilon=\left(\frac{\int_{t_{1}}^{t_{2}}\left(C_{\exp }(t)-C(t)\right)^{2} d t}{\int_{t_{1}}^{t_{2}}\left(C_{\exp }(t)\right)^{2} d t}\right)^{1 / 2}$

where $t_{1}$ and $t_{2}$ correspond to the times at the front and latter $10 \%$ peak heights, respectively, of the measured response curve.

\section{Experimental}

\subsection{Materials}


$\operatorname{Pd}(\text { acac })_{2}$ with purity of $99 \%$ and $\mathrm{Co}(\text { acac })_{3}$ with $98 \%$ were purchased from Aldrich and Wako, respectively. They were used as received without further purification. Carbon dioxide with a purity > 99.99 vol.\% was obtained from Marukyo Sanso Co., Japan.

\subsection{Apparatus and procedure}

The experimental apparatus and procedures are substantially the same as those in the previous studies [6,7]. Supercritical carbon dioxide was passed through a poly(ethylene glycol) coated capillary column (UACW-15W-1.0F, the Frontier Laboratories Ltd. Japan, polymer thickness of $1 \mu \mathrm{m}, R=0.265 \mathrm{~mm}, L=16.293 \mathrm{~m}$, and $R_{\text {coil }}=0.155 \mathrm{~m}$ ) at a constant flow rate fed by a syringe pump (260D, ISCO, USA). In this study, each metal complex was dissolved in supercritical carbon dioxide prior to an injection (injector model 7520 equipped with a $0.2 \mu \mathrm{L}$ rotor, Rheodyne, USA). The temperature of the water bath and the pressure of the system were controlled within $0.01 \mathrm{~K}$ and $0.005 \mathrm{MPa}$, respectively. After the desired temperature, pressure and flow rate had become stabilized, the system was held under the same condition at least more 2 hours before an injection. Response curves, as time change of the tracer concentration, in terms of absorbance were monitored with a high pressure multi-UV-Vis detector by scanning at wavelengths from 195 to $650 \mathrm{~nm}$ with increments of 1 $\mathrm{nm}$ and time interval of $1.6 \mathrm{~s}$ for each measurement. In this study, only a single pulse of each metal acetylacetonate dissolved in supercritical carbon dioxide was loaded for each run. The $D e S c^{1 / 2}$ values indicating a criterion of the secondary flow effect were mostly lower than 8 , 9.9 at the maximum, where $D e$ and $S c$ are the Dean number and the Schmidt number, respectively. The Reynolds and the Schmidt numbers ranged from 22 to 95 and from 5 to 21 for $\mathrm{Pd}(\mathrm{acac})_{2}$, and from 21 to 77 and from 7 to 23 for $\mathrm{Co}(\mathrm{acac})_{3}$, respectively. 


\section{Results and discussion}

The $D_{12}$ data were measured for $\mathrm{Pd}(\mathrm{acac})_{2}$ at $308.15,313.15,323.15,333.15$ and 343.15 $\mathrm{K}$ and pressures from 8.5 to $40.0 \mathrm{MPa}$, and for $\mathrm{Co}(\mathrm{acac})_{3}$ at 313.15 and $343.15 \mathrm{~K}$ and 9.7 to 40.0 $\mathrm{MPa}$ in supercritical carbon dioxide using the CIR technique. The $D_{12}$ and $k$ values are presented in Table 1, together with the $\varepsilon$ values.

Fig. 1 illustrates the effects of the wavelength from 195 to $350 \mathrm{~nm}$ on (a) absorbance at the maximum peak height, $A_{\max }$, (b) $A_{\max } /\left(\mathrm{u}_{0} \times(\right.$ peak area $\left.)\right)$, (c) $k$, (d) $D_{12}$, and (e) rms error $\varepsilon$ for $\mathrm{Pd}(\mathrm{acac})_{2}$ and $\mathrm{Co}(\mathrm{acac})_{3}$ at $313.15 \mathrm{~K}$ and $10.0 \mathrm{MPa}$. Since $D_{12}$ of a solute in a fluid is a physical property, it should not depend on wavelengths of the solute. However, the $D_{12}$ values obtained were greatly influenced by wavelengths in measurements because of the experimental noise or non-linearity of the detector. In the whole wavelength range, the $A_{\max }$ values for the two metal complexes are lower than 0.01 absorbance unit, and the values of $A_{\max } /\left(\mathrm{u}_{0} \times(\right.$ peak area $\left.)\right)$ indicating the linearity of detector were almost constant. However, at wavelengths higher than $260 \mathrm{~nm}$, the values of $A_{\max } /\left(\mathrm{u}_{0} \times(\right.$ peak area $\left.)\right)$ are slightly scattered, correspondingly the $\varepsilon$ values show larger values, and the determined $D_{12}$ values in the wavelength range were dependent on wavelength, especially for $\operatorname{Pd}(\mathrm{acac})_{2}$, as shown in Fig. 1(d). This is probably caused by the noise of the detector. On the other hand, the constant $k$ values were observed for both $\operatorname{Pd}(\mathrm{acac})_{2}$ and $\mathrm{Co}(\mathrm{acac})_{3}$ over the entire wavelength range. In this study, the wavelengths of $220 \mathrm{~nm}$ for $\mathrm{Pd}(\mathrm{acac})_{2}$ and $225 \mathrm{~nm}$ for $\mathrm{Co}(\mathrm{acac})_{3}$ were chosen to analyze response curves having moderate absorbance that resulted in a small fitting error and constant values of $k$ and $D_{12}$ around the wavelengths.

Fig. 2 shows the measured and calculated response curves by the CIR model for (a) $\operatorname{Pd}(\mathrm{acac})_{2}$ at $220 \mathrm{~nm}$ and (b) $\mathrm{Co}(\mathrm{acac})_{3}$ at $225 \mathrm{~nm}$ in supercritical carbon dioxide at $313.15 \mathrm{~K}$ and 10.0 MPa. The measured curves do not show tailing, and are well represented by the calculated curves with $\varepsilon<1 \%$ for both of $\mathrm{Pd}(\mathrm{acac})_{2}$ and $\mathrm{Co}(\mathrm{acac})_{3}$. The obtained values of 
$D_{12}$ and $\varepsilon$ under the condition were $1.097 \times 10^{-8} \mathrm{~m}^{2} / \mathrm{s}$ and $0.69 \%$ for $\mathrm{Pd}(\mathrm{acac})_{2}$, and $0.980 \times 10^{-8}$ $\mathrm{m}^{2} / \mathrm{s}$ and $0.51 \%$ for $\mathrm{Co}(\mathrm{acac})_{3}$, respectively.

The effects of pressure and temperature on $D_{12}$ of $\operatorname{Pd}(\mathrm{acac})_{2}$ are presented in Figs 3(a) and (b), respectively. The $D_{12}$ values of $\operatorname{Pd}(\mathrm{acac})_{2}$ were examined isothermally as a function of pressure at $308.15,313.15,323.15,333.15$ and $343.15 \mathrm{~K}$, and isobarically as a function of temperature at $15.0,20.0,25.0,30.0,35.0$ and $40.0 \mathrm{MPa}$. It was observed that the $D_{12}$ data decreased with increasing pressure at constant temperature, and increased with increasing temperature at constant pressure. The lower pressure sensitivity of $D_{12}$ in the range of high pressure, as shown in Fig. 3(a), is probably due to no drastical changes in fluid density and viscosity. A high temperature dependence on $D_{12}$ at constant pressure, as indicated in Fig. 3(b), can be observed.

Figs 4 and 5 show a large density dependency on $D_{12}$ and $k$ for $\operatorname{Pd}(\operatorname{acac})_{2}$ and $\mathrm{Co}(\mathrm{acac})_{3}$ at constant temperature of $313.15 \mathrm{~K}$ in supercritical carbon dioxide, together with literature data of lipids such as arachidonic acid [8] having molecular weight of 304.5 and monoolein [9] having molecular weight of 356.5. The densities of carbon dioxide were obtained with the equation of Span and Wagner [10]. It was found from Figs 4(a) and (b) that the $D_{12}$ values of $\mathrm{Pd}(\mathrm{acac})_{2}$ having molecular weight of 304.6 are larger than those of $\mathrm{Co}(\mathrm{acac})_{3}$ having that of 356.3, as expected. In addition, it was observed that the $D_{12}$ values of $\mathrm{Pd}(\mathrm{acac})_{2}$ were larger by about $28 \%$ than those of arachidonic acid [8] having similar molecular weight. On the other hand, the $k$ values of $\operatorname{Pd}(\operatorname{acac})_{2}$ were lower than those of arachidonic acid [8] (see Fig. 5(a)). The same tendency can be observed for $\mathrm{Co}(\mathrm{acac})_{3}$ and monoolein [9] having similar molecular weight (Fig. 5(b)). The difference in $D_{12}$ values for $\mathrm{Co}(\mathrm{acac})_{3}$ and monoolein is about $18 \%$. For each case, the $D_{12}$ values of metal complex show larger values than those of lipid having similar molecular weight. The difference may be attributed to those in molecular shape and polarity. 
As shown in Figs 5(a) and (b), the $k$ values were correlated with carbon dioxide density $\rho$, as has been found for various compounds [5,6,8,9,11-17]. All $k$ values for $\operatorname{Pd}(\mathrm{acac})_{2}$ and $\mathrm{Co}(\mathrm{acac})_{3}$ measured in this study were well expressed by Eq. (4).

$$
\ln k=\sum_{i=0}^{3} a_{i}\left(\ln \rho\left[\mathrm{kg} / \mathrm{m}^{3}\right]\right)^{i}
$$

where $k$ is the retention factor with no dimension, $a_{\mathrm{i}}$ values are coefficients of the polynomial correlation for each complex at constant temperature, as listed in Table 2, together with the average absolute relative deviation (AARD) values.

The validity of the correlation in Eq. (5), on the basis of the hydrodynamic approach, for various compounds in supercritical carbon dioxide has been demonstrated [5,6,8,9,11-19]

$\frac{D_{12}}{T}=\alpha \eta^{\beta}$

where unites of $D_{12}, T$ and $\eta$ are $\mathrm{m}^{2} \mathrm{~s}^{-1}, \mathrm{~K}$ and $\mathrm{Pa}$ s, respectively. The values of $\alpha$ and $\beta$ are constant, and depend on the solute and the fluid system. Fig. 6 shows the validity of Eq. (5) in plot of $D_{12} / T$ versus carbon dioxide viscosity $\eta$ for all $D_{12}$ data of $\operatorname{Pd}(\operatorname{acac})_{2}$ and $\operatorname{Co}(\text { acac })_{3}$ in supercritical carbon dioxide, measured in this study, together with the curve fitting errors $\varepsilon$. The viscosities of carbon dioxide were calculated by the method of Fenghour et al. [20]. As shown in Fig. 6(b), the errors seem to be independent of viscosity, and most $\varepsilon$ values were smaller than $1 \%$. This indicates that the measured response curves were well represented by the model, and the $D_{12}$ data of $\mathrm{Pd}(\mathrm{acac})_{2}$ and $\mathrm{Co}(\mathrm{acac})_{3}$ measured by the CIR method in this study can be considered quite reliable. As seen in Fig. 6(a), the plots are well represented by each straight line in Eq. (5) for the $D_{12}$ data of $\mathrm{Pd}(\mathrm{acac})_{2}$ and $\mathrm{Co}(\mathrm{acac})_{3}$ measured in this study. As presented in Table 3, the AARD values are $2.9 \%$ and $1.3 \%$ for 125 data points of $\operatorname{Pd}(\mathrm{acac})_{2}$ and 38 data points of $\mathrm{Co}(\mathrm{acac})_{3}$, respectively. In addition, since the $\beta$ values are not equal to minus unity, the present $D_{12}$ data of metal acetylacetonates in supercritical carbon dioxide do not support the Stokes-Einstein relationship. 


\section{Conclutions}

Binary diffusion coefficients and retention factors of metal acetylacetonates at infinite dilution in supercritical carbon dioxide were measured by the chromatographic impulse response method. Measurements for palladium(II) acetylacetonate have been made at 308.15, $313.15,323.15,333.15$, and $343.15 \mathrm{~K}$ over the pressure range of 8.5 to $40.0 \mathrm{MPa}$, and for cobalt (III) acetylacetonate at 313.15 and $333.15 \mathrm{~K}$, and at 9.7 to $40.0 \mathrm{MPa}$. The influences of pressure, temperature, density, and viscosity on the $D_{12}$ values were examined. In addition, it was observed that the $D_{12}$ values of acetylacetonates were larger than those of lipids with similar molecular weights; namely, palladium(II) acetylacetonate to arachidonic acid, and cobalt (III) acetylacetonate to monoolein. The measured $D_{12}$ data of the metal acetylacetonates in supercritical carbon dioxide were correlated by the hydrodynamic equation $D_{12} / T$ as a function of viscosity with average absolute relative deviation of $2.9 \%$ and $1.3 \%$ for 125 data points for $\mathrm{Pd}(\mathrm{acac})_{2}$ and 38 data points for $\mathrm{Co}(\mathrm{acac})_{3}$, respectively. Moreover, the retention factors were also correlated with $\mathrm{CO}_{2}$ density at each temperature.

\section{List of symbols}

$\begin{array}{ll}\text { AARD } \% & \text { average absolute relative deviation } \\ C(t) & \text { cross-sectional average concentration given by Eq.(1) } \\ C_{\text {exp }}(t) & \text { concentration measured experimentally } \\ D_{12} & \text { binary diffusion coefficient } \\ D e & \text { Dean number }=\left(2 \rho u_{0} R / \eta\right)\left(R / R_{\text {coil }}\right)^{1 / 2} ; R_{\text {coil }}: \text { coil radius of diffusion column; } \\ k & \text { retention factor for solute in polymer stationary phase to supercritical fluid phase } \\ L & \text { distance between injection point and detection point } \\ m & \text { injected amount of solute }\end{array}$




$\begin{array}{ll}N & \text { number of data points } \\ P & \text { pressure } \\ R & \text { radius of diffusion column } \\ S c & \text { Schmidt number }=\eta /\left(\rho D_{12}\right) \\ T & \text { temperature } \\ t & \text { time } \\ u_{0} & \text { average velocity of fluid } \\ \alpha, \beta & \text { constants in Eq. (5) } \\ \varepsilon & \text { fitting error defined by Eq. (3) } \\ \eta & \text { viscosity } \\ \rho & \text { density }\end{array}$

\section{Acknowledgements}

This study was supported by Grants-in-Aid \#18760565 and \#18560725 from the Ministry of Education, Culture, Sports, Science and Technology of Japan. 


\section{References}

[1] E. Ramsey, Q. Sun, Z. Zhang, C. Zhang, W. Gou, J. Environ. Sci. 21 (2009) 720-726.

[2] F. Cansell, C. Aymonier, A. Loppinet-Serani, Curr. Opin. Solid State Mater. Sci. 7 (2003) 331-340.

[3] Y. Zhang, C. Erkey, J. Supercrit. Fluids 38 (2006) 252-267.

[4] X. Yang, M.A. Matthews, J. Chem. Eng. Data 46 (2001) 588-595.

[5] T. Funazukuri, C.Y. Kong, N. Murooka, S. Kagei, Ind. Eng. Chem. Res. 39 (2000) $4462-4469$.

[6] C.Y. Kong, T. Funazukuri, S. Kagei, J. Chromatogr. A 1035 (2004) 177-193.

[7] C.Y. Kong, T. Funazukuri, S. Kagei, J. Supercrit. Fluids 44 (2008) 294-300.

[8] T. Funazukuri, C.Y. Kong, T. Kikuchi, S. Kagei, J. Chem. Eng. Data 48 (2003) 684-688.

[9] T. Funazukuri, C.Y. Kong, S. Kagei, Fluid Phase Equilib. 219 (2004) 67-73.

[10] R. Span, W. Wagner, J. Phys. Chem. Ref. Data 25 (1996) 1509-1596.

[11] T. Funazukuri, C.Y. Kong, S. Kagei, Ind. Eng. Chem. Res. 41 (2002) 2812-2818.

[12] T. Funazukuri, C.Y. Kong, S. Kagei, Fluid Phase Equilib. 206 (2003) 163-178.

[13] T. Funazukuri, C.Y. Kong, S. Kagei, J. Supercrit. Fluids 27 (2003) 85-96.

[14] C.Y. Kong, N.R.W. Withanage, T. Funazukuri, S. Kagei, J. Chem. Eng. Data 50 (2005) 1635-1640.

[15] C.Y. Kong, N.R.W. Withanage, T. Funazukuri, S. Kagei, J. Supercrit. Fluids 37 (2006) 63-71.

[16] C.Y. Kong, M. Mori, T. Funazukuri, S. Kagei, Anal. Chem. 22 (2006) 1431-1436.

[17] T. Funazukuri, C.Y. Kong, S. Kagei, J. Chromatogr. A 1037 (2004) 411-429.

[18] T. Funazukuri, C.Y. Kong, S. Kagei, J. Supercrit. Fluids 38 (2006) 201-210.

[19] T. Funazukuri, C.Y. Kong, S. Kagei, J. Supercrit. Fluids 46 (2008) 280-284.

[20] A. Fenghour, W.A. Wakeham, V. Vesovic, J. Phys. Chem. Ref. Data 27 (1998) 31-44. 
Table 1. Measured $D_{12}$ and $k$ values for $\operatorname{Pd}(\mathrm{acac})_{2}$ and $\mathrm{Co}(\mathrm{acac})_{3}$ in supercritical carbon dioxide, together with fitting errors $\varepsilon$

\begin{tabular}{|c|c|c|c|c|c|}
\hline Solute & $T(\mathrm{~K})$ & $P(\mathrm{MPa})$ & $D_{12}\left(10^{-8} \mathrm{~m}^{2} / \mathrm{s}\right)$ & $k$ & $10^{2} \varepsilon$ \\
\hline \multirow[t]{36}{*}{$\operatorname{Pd}(\mathrm{acac})_{2}$} & 308.15 & 8.5 & 1.136 & 1.469 & 0.76 \\
\hline & & 8.5 & 1.130 & 1.466 & 0.84 \\
\hline & & 8.5 & 1.123 & 1.478 & 0.91 \\
\hline & & 9.0 & 1.033 & 1.009 & 0.74 \\
\hline & & 9.0 & 1.022 & 1.000 & 1.00 \\
\hline & & 9.5 & 0.977 & 0.795 & 0.96 \\
\hline & & 10.0 & 0.940 & 0.676 & 0.54 \\
\hline & & 10.0 & 0.949 & 0.675 & 0.67 \\
\hline & & 11.0 & 0.901 & 0.536 & 0.98 \\
\hline & & 12.0 & 0.858 & 0.452 & 0.54 \\
\hline & & 15.0 & 0.786 & 0.327 & 0.38 \\
\hline & & 15.0 & 0.782 & 0.325 & 0.68 \\
\hline & & 16.0 & 0.766 & 0.303 & 0.48 \\
\hline & & 20.0 & 0.707 & 0.232 & 0.69 \\
\hline & & 25.0 & 0.666 & 0.192 & 0.21 \\
\hline & & 25.0 & 0.660 & 0.189 & 0.37 \\
\hline & & 30.0 & 0.613 & 0.160 & 0.54 \\
\hline & & 35.0 & 0.578 & 0.145 & 0.74 \\
\hline & & 40.0 & 0.561 & 0.131 & 0.32 \\
\hline & & 40.0 & 0.551 & 0.132 & 0.63 \\
\hline & 313.15 & 9.5 & 1.173 & 1.776 & 0.89 \\
\hline & & 9.5 & 1.190 & 1.773 & 0.83 \\
\hline & & 9.7 & 1.154 & 1.478 & 0.87 \\
\hline & & 9.7 & 1.133 & 1.470 & 0.73 \\
\hline & & 9.7 & 1.120 & 1.477 & 0.64 \\
\hline & & 10.0 & 1.089 & 1.184 & 0.25 \\
\hline & & 10.0 & 1.097 & 1.181 & 0.69 \\
\hline & & 11.0 & 0.971 & 0.767 & 0.47 \\
\hline & & 11.0 & 1.001 & 0.767 & 0.13 \\
\hline & & 11.0 & 0.995 & 0.769 & 0.10 \\
\hline & & 12.0 & 0.933 & 0.590 & 0.41 \\
\hline & & 13.0 & 0.902 & 0.490 & 0.30 \\
\hline & & 14.0 & 0.881 & 0.423 & 0.43 \\
\hline & & 15.0 & 0.847 & 0.374 & 0.49 \\
\hline & & 15.0 & 0.852 & 0.373 & 0.62 \\
\hline & & 15.0 & 0.845 & 0.375 & 0.57 \\
\hline
\end{tabular}




\begin{tabular}{|c|c|c|c|c|}
\hline & 15.0 & 0.843 & 0.374 & 0.38 \\
\hline & 15.0 & 0.841 & 0.372 & 0.17 \\
\hline & 16.0 & 0.828 & 0.338 & 0.28 \\
\hline & 17.0 & 0.801 & 0.305 & 0.29 \\
\hline & 17.0 & 0.795 & 0.310 & 0.28 \\
\hline & 18.0 & 0.774 & 0.274 & 0.34 \\
\hline & 18.0 & 0.777 & 0.286 & 0.17 \\
\hline & 19.0 & 0.755 & 0.266 & 0.28 \\
\hline & 20.0 & 0.750 & 0.251 & 0.33 \\
\hline & 21.0 & 0.742 & 0.236 & 0.38 \\
\hline & 21.0 & 0.726 & 0.238 & 0.46 \\
\hline & 21.0 & 0.733 & 0.235 & 0.14 \\
\hline & 22.0 & 0.722 & 0.224 & 0.59 \\
\hline & 24.0 & 0.701 & 0.207 & 0.27 \\
\hline & 24.0 & 0.691 & 0.204 & 0.61 \\
\hline & 25.0 & 0.689 & 0.194 & 0.40 \\
\hline & 30.0 & 0.648 & 0.164 & 0.39 \\
\hline & 30.0 & 0.638 & 0.174 & 0.27 \\
\hline & 35.0 & 0.610 & 0.149 & 0.37 \\
\hline & 35.0 & 0.607 & 0.143 & 0.43 \\
\hline & 40.0 & 0.589 & 0.130 & 0.47 \\
\hline & 40.0 & 0.582 & 0.131 & 0.22 \\
\hline 323.15 & 12.0 & 1.271 & 1.439 & 0.67 \\
\hline & 13.0 & 1.150 & 0.908 & 0.40 \\
\hline & 13.0 & 1.165 & 0.929 & 0.31 \\
\hline & 15.0 & 1.025 & 0.550 & 0.24 \\
\hline & 15.0 & 1.020 & 0.547 & 0.13 \\
\hline & 20.0 & 0.881 & 0.294 & 0.75 \\
\hline & 20.0 & 0.890 & 0.307 & 0.17 \\
\hline & 25.0 & 0.799 & 0.218 & 0.35 \\
\hline & 30.0 & 0.744 & 0.175 & 0.25 \\
\hline & 35.0 & 0.704 & 0.149 & 0.22 \\
\hline & 40.0 & 0.658 & 0.128 & 0.70 \\
\hline & 40.0 & 0.667 & 0.134 & 0.44 \\
\hline 333.15 & 14.0 & 1.403 & 1.436 & 0.66 \\
\hline & 14.0 & 1.346 & 1.434 & 0.73 \\
\hline & 15.0 & 1.272 & 0.986 & 0.47 \\
\hline & 15.0 & 1.286 & 0.991 & 0.75 \\
\hline & 15.0 & 1.276 & 0.977 & 0.16 \\
\hline & 15.0 & 1.333 & 1.011 & 0.57 \\
\hline & 15.0 & 1.293 & 0.976 & 0.54 \\
\hline
\end{tabular}




\begin{tabular}{|c|c|c|c|c|}
\hline & 16.0 & 1.217 & 0.750 & 0.67 \\
\hline & 17.0 & 1.154 & 0.601 & 0.37 \\
\hline & 17.0 & 1.159 & 0.590 & 0.36 \\
\hline & 17.5 & 1.127 & 0.535 & 0.81 \\
\hline & 17.5 & 1.130 & 0.539 & 0.93 \\
\hline & 17.5 & 1.138 & 0.544 & 0.38 \\
\hline & 18.0 & 1.123 & 0.500 & 0.38 \\
\hline & 20.0 & 1.038 & 0.380 & 0.48 \\
\hline & 20.0 & 1.055 & 0.376 & 0.29 \\
\hline & 20.0 & 1.045 & 0.377 & 0.43 \\
\hline & 20.0 & 1.043 & 0.380 & 0.87 \\
\hline & 20.0 & 1.048 & 0.381 & 0.26 \\
\hline & 20.0 & 1.053 & 0.380 & 0.40 \\
\hline & 20.0 & 1.055 & 0.385 & 0.78 \\
\hline & 20.0 & 1.068 & 0.379 & 0.63 \\
\hline & 22.0 & 0.991 & 0.308 & 0.95 \\
\hline & 22.0 & 0.989 & 0.306 & 0.62 \\
\hline & 22.0 & 0.985 & 0.304 & 0.48 \\
\hline & 22.0 & 1.004 & 0.311 & 0.92 \\
\hline & 23.0 & 0.964 & 0.280 & 0.11 \\
\hline & 23.0 & 0.980 & 0.279 & 0.24 \\
\hline & 24.0 & 0.950 & 0.265 & 0.29 \\
\hline & 24.0 & 0.963 & 0.262 & 0.22 \\
\hline & 25.0 & 0.927 & 0.237 & 0.78 \\
\hline & 25.0 & 0.920 & 0.246 & 0.29 \\
\hline & 30.0 & 0.866 & 0.189 & 0.23 \\
\hline & 35.0 & 0.800 & 0.153 & 0.25 \\
\hline & 35.0 & 0.806 & 0.157 & 0.52 \\
\hline & 40.0 & 0.746 & 0.134 & 0.62 \\
\hline & 40.0 & 0.770 & 0.141 & 0.34 \\
\hline 343.15 & 17.0 & 1.369 & 0.965 & 0.89 \\
\hline & 17.0 & 1.362 & 0.961 & 0.55 \\
\hline & 17.0 & 1.354 & 0.954 & 0.40 \\
\hline & 17.0 & 1.378 & 0.952 & 0.29 \\
\hline & 20.0 & 1.225 & 0.511 & 0.51 \\
\hline & 20.0 & 1.211 & 0.507 & 0.40 \\
\hline & 25.0 & 1.050 & 0.282 & 0.38 \\
\hline & 25.0 & 1.063 & 0.287 & 0.17 \\
\hline & 25.0 & 1.085 & 0.288 & 0.22 \\
\hline & 25.0 & 1.057 & 0.286 & 0.45 \\
\hline & 25.0 & 1.065 & 0.286 & 0.23 \\
\hline & 30.0 & 0.958 & 0.205 & 0.19 \\
\hline
\end{tabular}




\begin{tabular}{|c|c|c|c|c|c|}
\hline & & 30.0 & 0.961 & 0.205 & 0.31 \\
\hline & & 30.0 & 0.970 & 0.204 & 0.35 \\
\hline & & 35.0 & 0.895 & 0.166 & 0.64 \\
\hline & & 35.0 & 0.891 & 0.166 & 0.17 \\
\hline & & 35.0 & 0.898 & 0.165 & 0.13 \\
\hline & & 40.0 & 0.846 & 0.141 & 0.36 \\
\hline \multirow[t]{35}{*}{$\mathrm{Co}(\mathrm{acac})_{3}$} & 313.15 & 9.7 & 1.037 & 1.048 & 0.38 \\
\hline & & 9.7 & 0.998 & 1.091 & 0.67 \\
\hline & & 10.0 & 0.980 & 0.859 & 0.51 \\
\hline & & 10.0 & 0.966 & 0.856 & 0.89 \\
\hline & & 11.0 & 0.877 & 0.531 & 0.39 \\
\hline & & 11.0 & 0.888 & 0.545 & 0.84 \\
\hline & & 11.0 & 0.874 & 0.552 & 0.98 \\
\hline & & 11.0 & 0.870 & 0.546 & 0.54 \\
\hline & & 13.0 & 0.770 & 0.351 & 0.90 \\
\hline & & 13.0 & 0.764 & 0.349 & 0.97 \\
\hline & & 13.0 & 0.786 & 0.334 & 1.13 \\
\hline & & 13.0 & 0.785 & 0.340 & 0.99 \\
\hline & & 18.0 & 0.686 & 0.195 & 0.89 \\
\hline & & 20.0 & 0.654 & 0.177 & 0.24 \\
\hline & & 20.0 & 0.658 & 0.176 & 0.47 \\
\hline & & 25.0 & 0.604 & 0.139 & 0.69 \\
\hline & & 25.0 & 0.582 & 0.139 & 0.55 \\
\hline & & 25.0 & 0.587 & 0.142 & 0.52 \\
\hline & & 30.0 & 0.571 & 0.114 & 0.23 \\
\hline & & 30.0 & 0.552 & 0.131 & 0.56 \\
\hline & & 30.0 & 0.567 & 0.119 & 0.10 \\
\hline & & 40.0 & 0.501 & 0.098 & 0.79 \\
\hline & & 40.0 & 0.511 & 0.106 & 0.79 \\
\hline & 333.15 & 15.0 & 1.058 & 0.662 & 0.47 \\
\hline & & 18.0 & 0.944 & 0.326 & 0.40 \\
\hline & & 20.0 & 0.866 & 0.250 & 0.82 \\
\hline & & 20.0 & 0.877 & 0.243 & 0.92 \\
\hline & & 25.0 & 0.761 & 0.172 & 0.81 \\
\hline & & 25.0 & 0.765 & 0.152 & 0.36 \\
\hline & & 25.0 & 0.785 & 0.162 & 0.36 \\
\hline & & 25.0 & 0.777 & 0.166 & 0.63 \\
\hline & & 30.0 & 0.690 & 0.128 & 0.94 \\
\hline & & 30.0 & 0.689 & 0.128 & 0.71 \\
\hline & & 30.0 & 0.703 & 0.126 & 0.84 \\
\hline & & 30.0 & 0.689 & 0.129 & 0.70 \\
\hline
\end{tabular}




\begin{tabular}{llll}
30.0 & 0.700 & 0.131 & 0.59 \\
40.0 & 0.615 & 0.101 & 0.41 \\
40.0 & 0.632 & 0.094 & 0.58 \\
\hline
\end{tabular}




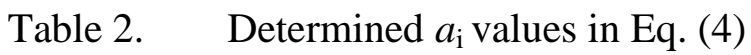

\begin{tabular}{|c|c|c|c|c|c|c|c|}
\hline Solute & $T(\mathrm{~K})$ & $a_{0}$ & $a_{1}$ & $a_{2}$ & $a_{3}$ & $A A R D(\%)^{\mathrm{a}}$ & $N^{\mathrm{b}}$ \\
\hline \multirow{5}{*}{$\mathrm{Pd}(\mathrm{acac})_{2}$} & 308.15 & -1689.0865 & 772.4500 & -116.9558 & 5.8608 & 0.6 & 20 \\
\hline & 313.15 & -1358.1553 & 626.7435 & -95.5976 & 4.8182 & 0.9 & 38 \\
\hline & 323.15 & -342.4442 & 169.4373 & -27.0101 & 1.3908 & 1.3 & 12 \\
\hline & 333.15 & -1439.8514 & 673.2468 & -104.1175 & 5.3243 & 1.2 & 37 \\
\hline & 343.15 & -1604.5016 & 751.1043 & -116.4198 & 5.9730 & 0.6 & 18 \\
\hline \multirow{2}{*}{$\mathrm{Co}(\mathrm{acac})_{3}$} & 313.15 & -2887.3212 & 1327.1167 & -202.5106 & 10.2565 & 2.2 & 23 \\
\hline & 333.15 & -1222.8282 & 583.1404 & -91.8158 & 4.7726 & 2.5 & 15 \\
\hline
\end{tabular}

a $\quad A A R D=\frac{100}{N} \sum_{i=1}^{N}\left|1-\frac{D_{12, \text { corr }}}{D_{12, \exp }}\right|(\%)$

b Number of data points

Table 3. Determined $\alpha$ and $\beta$ values in Eq. (5)

\begin{tabular}{lcccc} 
Solute & $\alpha$ & $\beta$ & $A A R D(\%)$ & $N$ \\
\hline $\operatorname{Pd}(\mathrm{acac})_{2}$ & $1.031 \times 10^{-14}$ & -0.822 & 2.9 & 125 \\
$\mathrm{Co}(\mathrm{acac})_{3}$ & $8.999 \times 10^{-15}$ & -0.819 & 1.3 & 38 \\
\hline
\end{tabular}




\section{Figure captions}

Fig. 1. Effects of wavelength on (a) absorbance at the maximum peak height, $A_{\max }$, (b) $A_{\max } /\left(\mathrm{u}_{0} \times(\right.$ peak area $\left.)\right),\left(\right.$ c) $k$, (d) $D_{12}$, and (e) rms error $\varepsilon$ for $\operatorname{Pd}(\operatorname{acac})_{2}\left(\triangle_{-}\right)$and $\mathrm{Co}(\mathrm{acac})_{3}(-\circ)$ in supercritical carbon dioxide at $313.15 \mathrm{~K}$ and $10.0 \mathrm{MPa}$.

Fig. 2. Comparison of experimental data (०) and calculated response curves (-) for (a) $\operatorname{Pd}(\mathrm{acac})_{2}$ at $220 \mathrm{~nm}$ and (b) $\mathrm{Co}(\mathrm{acac})_{3}$ at $225 \mathrm{~nm}$. The data are the same as in Fig. 1.

Fig. 3. $D_{12}$ of $\mathrm{Pd}(\mathrm{acac})_{2}$ in supercritical carbon dioxide as a function of (a) pressure at constant temperatures of $308.15 \mathrm{~K}(\circ), 313.15 \mathrm{~K}(\triangle), 323.15 \mathrm{~K}(\square), 333.15 \mathrm{~K}(\nabla)$ and $343.15 \mathrm{~K}(\diamond)$, and (b) temperature at constant pressures of $15.0 \mathrm{MPa}(\diamond), 20.0 \mathrm{MPa}$ $(\nabla), 25.0 \mathrm{MPa}(\square), 30.0 \mathrm{MPa}(\triangle), 35.0 \mathrm{MPa}(\circ)$ and $40.0 \mathrm{MPa}($ 汭).

Fig. 4. Effects of carbon dioxide density $\rho$ on $D_{12}$ at $313.15 \mathrm{~K}$ in supercritical carbon dioxide for (a) $\operatorname{Pd}(\operatorname{acac})_{2}(\Delta)$ in the present study and arachidonic acid $(\Delta)$ in the literature [8], and for $(\mathrm{b}) \mathrm{Co}(\mathrm{acac})_{3}(\bullet)$ in the present study and monoolein $(\mathrm{\circ})$ in the literature [9].

Fig. 5. Effects of carbon dioxide density $\rho$ on $k$ at $313.15 \mathrm{~K}$ in supercritical carbon dioxide for (a) $\operatorname{Pd}(\operatorname{acac})_{2}(\Delta)$ in the present study and arachidonic acid $(\Delta)$ in the literature [8], and for $(\mathrm{b}) \mathrm{Co}(\mathrm{acac})_{3}(\bullet)$ in the present study and monoolein $(\mathrm{o})$ in the literature [9].

Fig. 6. Plots of (a) $D_{12} / T$ and (b) $\varepsilon$ vs. carbon dioxide viscosity $\eta$ for all $D_{12}$ data measured of $\operatorname{Pd}(\mathrm{acac})_{2}$ at $308.15 \mathrm{~K}(\triangle), 313.15 \mathrm{~K}(\circ), 323.15 \mathrm{~K}(\nabla), 333.15 \mathrm{~K}(\square), 343.15 \mathrm{~K}(\diamond)$, and for $\mathrm{Co}(\mathrm{acac})_{3}$ at $313.15 \mathrm{~K}(\bullet)$ and $343.15 \mathrm{~K}(\bullet)$ in this study. 

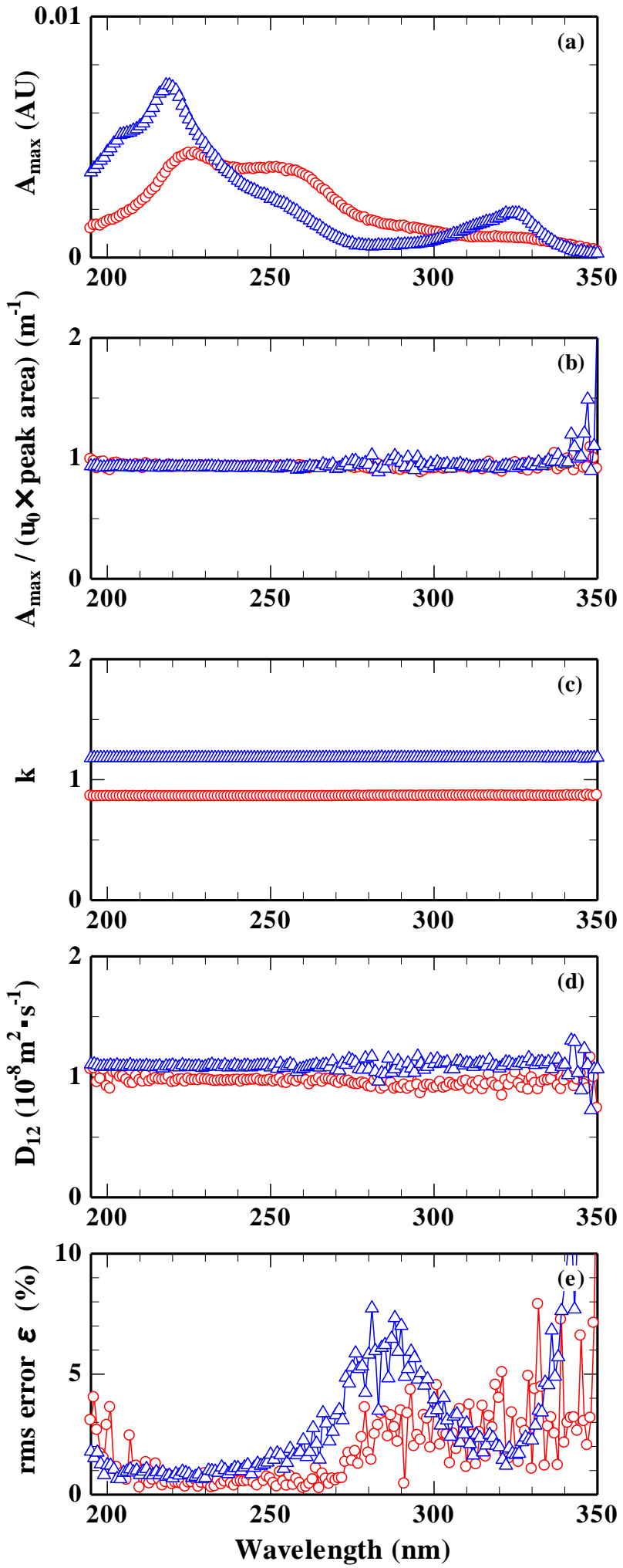

Fig. 1 

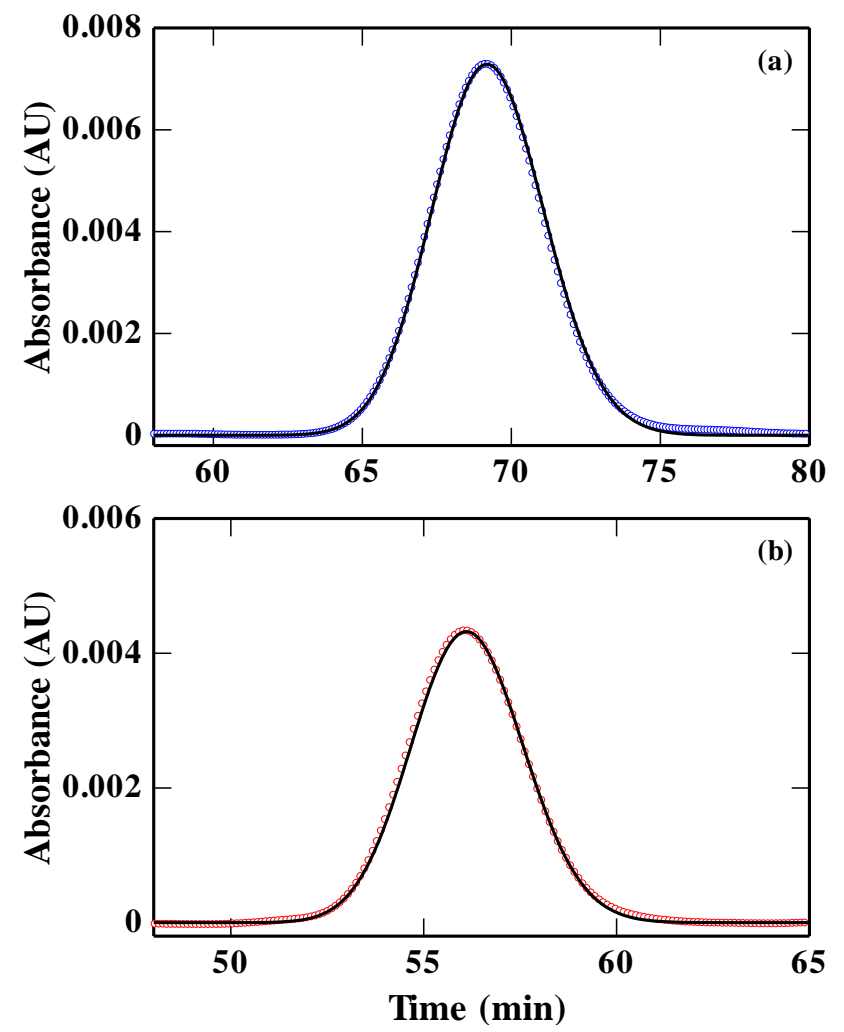

Fig. 2 

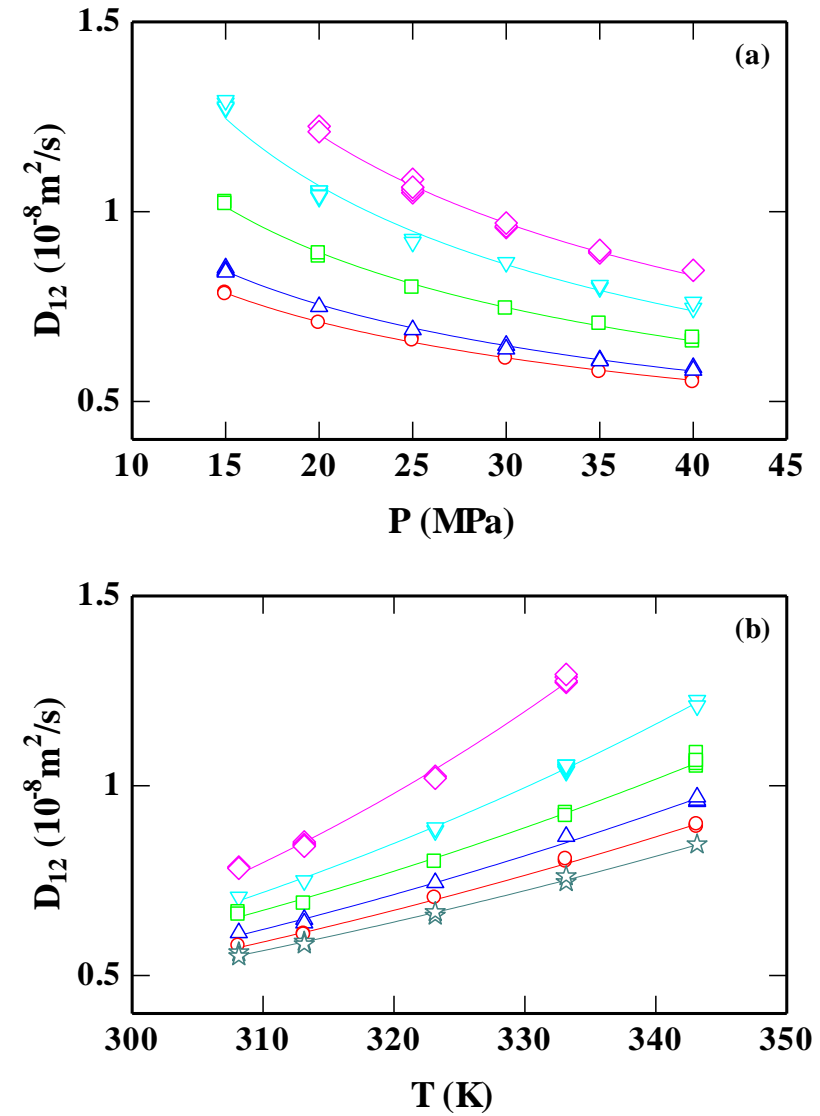

Fig. 3 

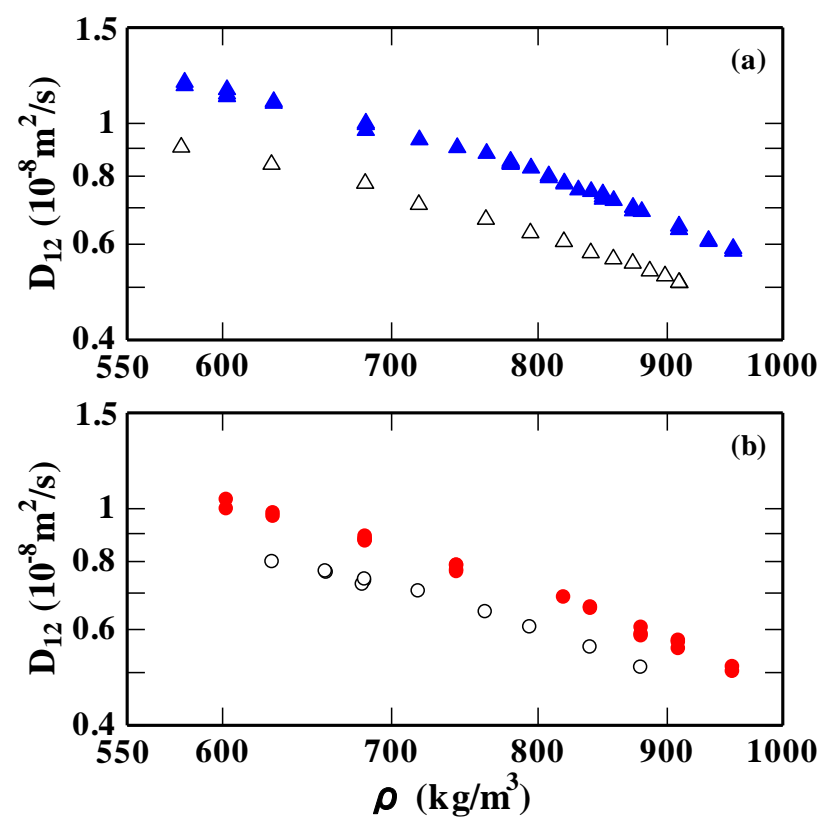

Fig. 4 


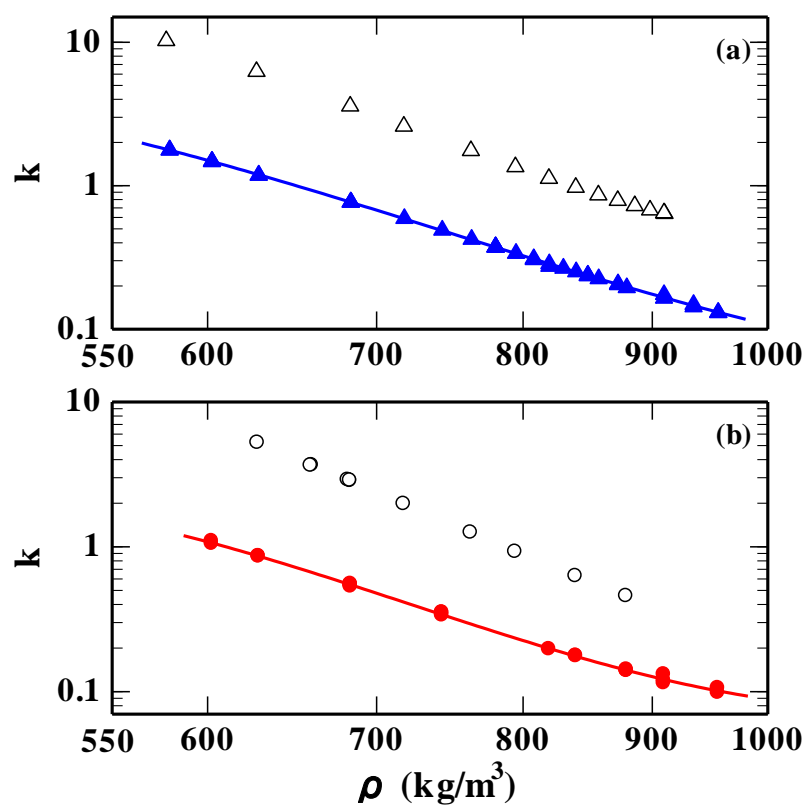

Fig. 5 

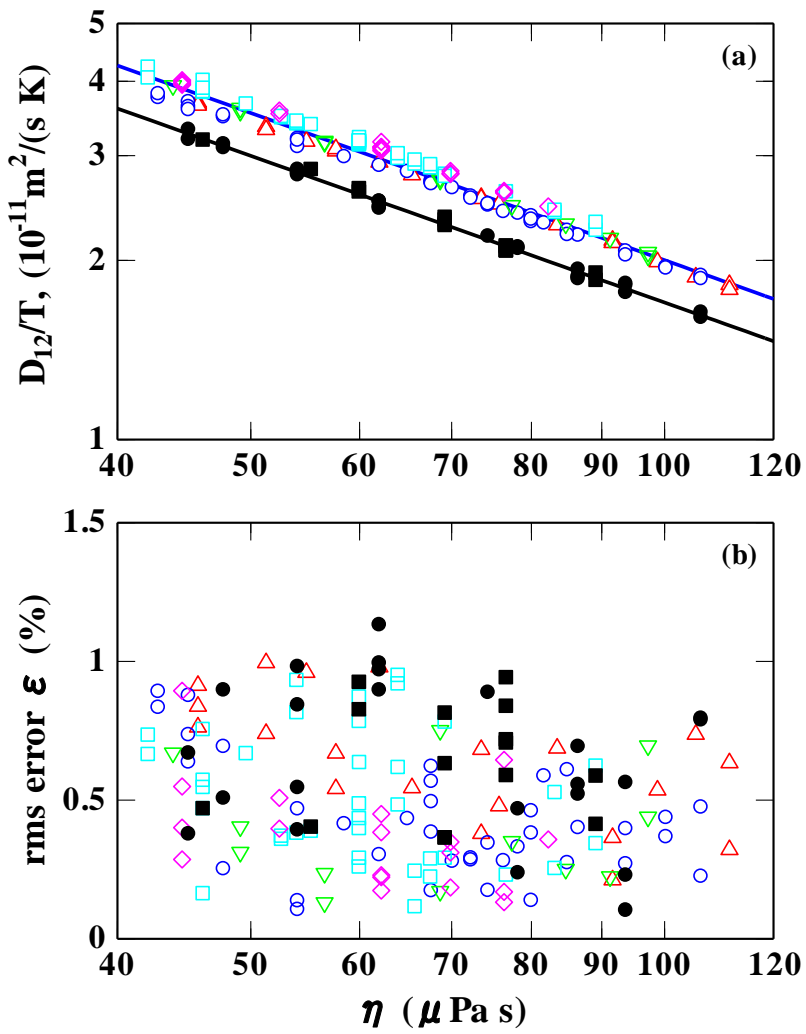

Fig. 6 